\title{
Desdobramento da Função Qualidade (QFD) na Avaliação da Qualidade do Carvão Vegetal Utilizado para Cocção de Alimentos
}

\author{
Ananias Francisco Dias Júnior ${ }^{1}$, Carlos Rogério Andrade ${ }^{2}$, \\ José Otávio Brito ${ }^{3}$, Marcos Milan ${ }^{4}$
}

\author{
${ }^{1}$ Programa de Pós-Graduação em Recursos Florestais, Escola Superior de Agricultura "Luiz de Queiroz" - ESALQ, \\ Universidade de São Paulo - USP, Piracicaba/SP, Brasil \\ ${ }^{2}$ Universidade Federal de Góias - UFG, Jataí/GO, Brasil \\ ${ }^{3}$ Departamento de Ciências Florestais, Escola Superior de Agricultura “Luiz de Queiroz" - ESALQ, \\ Universidade de São Paulo - USP, Piracicaba/SP, Brasil \\ ${ }^{4}$ Departamento de Biossistemas, Escola Superior de Agricultura "Luiz de Queiroz" - ESALQ \\ Universidade de São Paulo - USP, Piracicaba/SP, Brasil
}

\section{RESUMO}

O carvão vegetal é bastante utilizado para cocção (churrasco) nas residências brasileiras. Todavia, a sua comercialização é feita sem que haja um levantamento das reais necessidades dos consumidores desse insumo. O desdobramento da função qualidade (QFD) é um método sugerido para alcançar a qualidade identificando os desejos e exigências do consumidor. Assim, o presente trabalho teve por objetivo avaliar a aplicabilidade desse método no levantamento da qualidade do carvão vegetal comercializado para cocção no município de Piracicaba, SP. Os resultados mostram que as características relacionadas à embalagem do carvão vegetal se encontram entre as mais importantes características de apresentação do produto. A metodologia QFD mostrou-se, do ponto de vista do consumidor, uma ferramenta útil para definição da melhor qualidade do carvão vegetal utilizado para cocção de alimentos.

Palavras-chave: ferramentas de qualidade, qualidade do carvão vegetal, consumidor.

\section{Quality Function Deployment (QFD) in the Evaluation of Charcoal Quality Used for Food Cooking}

\begin{abstract}
Charcoal is widely used for cooking (barbecue) in Brazilian homes. However, its marketing is done without previous survey of the real needs of consumers of this input. The Quality Function Deployment (QFD) is a method suggested for achieving quality by identifying the desires and demands of consumers. The present study aimed to evaluate the applicability of this method in the quality surveying of charcoal for cooking commercialized in the municipality of Piracicaba, Sao Paulo state. The results show that the characteristics related to the packaging of charcoal are among the most important features of the product presentation. From the point of view of the consumer, the QFD methodology was a useful tool for defining the best quality charcoal used for cooking food.
\end{abstract}

Keywords: quality tools, quality charcoal grill, consumer. 


\section{INTRODUÇÃO}

O Brasil é o maior produtor e consumidor mundial de carvão vegetal. Em 2012, foram consumidos cerca de 33 milhões de metros cúbicos desse insumo, sendo que mais de dois terços desse volume foi destinado às indústrias siderúrgicas e metalúrgicas, sobretudo no Estado de Minas Gerais (Brasil, 2013). O carvão vegetal também é utilizado para outros fins, tais como: cocção de alimentos, lareiras, termoelétricas, indústria cimenteira, purificação de água e bebidas, indústria farmacêutica, filtros de máscaras contra gases, dentre outros.

Segundo Brito (2002), Ribeiro \& Vale (2006) e Rosa et al. (2012) o carvão vegetal para ser considerado de boa qualidade para uso doméstico deve reunir características como alta densidade, alto teor de carbono fixo, alto poder calorífico, baixo teor de umidade, baixo teor de materiais voláteis e baixo teor de cinzas.

Nos Estados Unidos, por exemplo, é de longa data a existência de trabalhos acerca de aparatos e da qualidade do carvão vegetal para fins de cocção (churrasco) (Warnes, 2008). Um exemplo de norma na Europa é o da Association Française de Normalisation - AFNOR (2005) - Appareils, combustibles solides et allume-barbecue pour la cuisson au barbecue, que descreve aspectos de qualidade para carvão vegetal e briquetes utilizados para uso na cocção de alimentos. No Brasil, o único mecanismo que estabelece diretrizes para controle de qualidade de carvão vegetal para cocção de alimentos é a da Secretaria de Agricultura e Abastecimento do Estado de São Paulo. Trata-se do Selo São Paulo - Carvão Premium, promulgado pela Resolução n. 10 SAA, de 11 de julho de 2003. Ela visa determinar um padrão de qualidade para o carvão vegetal para uso doméstico, incluindo indicadores para teor de umidade, teor de carbono fixo, teor de materiais voláteis, teor de cinzas, tamanho das peças, mão de obra utilizada, dentre outros (São Paulo, 2003).

Além desses atributos técnicos para qualificação do uso do carvão vegetal, questões inerentes às embalagens do produto, como tamanho, composição (papel ou plástico), presença de acendedores, entre outros, não são levadas em conta. Saber inicialmente o "que" os consumidores de carvão vegetal necessitam para depois definir "como" atendê-los é um conceito pouco difundido na área de comercialização de produtos florestais e apresentado neste trabalho.

Para a identificação das melhores formas de se agregar valor ao carvão vegetal, é necessário compreender a interação entre as propriedades da madeira, os processos e recursos utilizados para sua produção, levando-se em conta as reais necessidades dos consumidores e a aplicação de métodos para transformar essas necessidades em requisitos a serem incorporados nesse insumo energético.

Diante disso, o Quality Function Deployment (QFD) ou, em português, desdobramento da função qualidade, é uma metodologia que possibilita operacionalizar o planejamento da qualidade, onde as necessidades e desejos são transformados em características de produto e, depois, em especificações de produção. Estas necessidades são também utilizadas na definição de pontos de controle incorporados aos procedimentos operacionais, para garantir que a produção esteja de acordo com as especificações (Cheng \& Melo, 2007; Carnevalli \& Miguel, 2008; Doliveira \& Silva, 2008; Pinto \& Paiva, 2010).

O QFD é um método para desenvolver a qualidade visando a satisfação de quem consome, sendo o seu principal ponto o gráfico denominado "casa da qualidade", onde as exigências dos clientes sobre o "que", se traduzem em características de design em "como" sobre a base de pesquisa de mercado e experiências passadas (Milan et al. 2003; Lucas Filho et al. 2010).

Diante do exposto, o presente trabalho teve por objetivo avaliar a aplicabilidade do método QFD no levantamento da qualidade do carvão vegetal comercializado no município de Piracicaba, SP para fins de cocção de alimentos (churrasco).

\section{MATERIAL E MÉTODOS}

Para identificar o perfil e as reais necessidades dos consumidores de carvão vegetal para cocção, especificamente para a preparação de churrasco, foram realizadas 175 entrevistas mediante aplicação de questionários próprios, direcionadas aos clientes de uma loja de uma grande rede de supermercados, localizada no município de Piracicaba, SP.

A abordagem da pesquisa para aplicação do questionário buscou identificar, dentre os clientes, aqueles que buscavam comprar ou estavam realizando 
pesquisas com intenção de compra de carvão vegetal no estabelecimento comercial. O questionário foi construído obedecendo a uma ordem lógica na elaboração das perguntas, cujo roteiro continha perguntas mistas abertas (respostas livres) e de livre escolha. Os dados incluíram informações sobre as características do carvão vegetal desejado, matéria-prima, embalagens, peso e problemas já encontrados durante o seu uso em churrasco. O instrumento de coleta de dados proporcionou uma interação efetiva entre o informante e a pesquisa.

Após a avaliação dos questionários, as principais necessidades dos consumidores foram identificadas e discutidas por um grupo composto por produtores, distribuidores, comerciantes, engenheiros florestais, técnicos e consumidores ligados à cadeia produtiva do carvão vegetal. Dessa forma, por meio de uma sessão de brainstorming, conhecida por "tempestade de ideias", foram desdobradas as principais qualidades exigidas para formação da matriz de qualidade.

O QFD é uma ferramenta que pode ser utilizada tanto na melhoria de produtos existentes, como ainda possibilita a realização de correções de problemas detectados através de informações geradas pelos próprios clientes. Assim, o produto avaliado (denominado "nosso produto") foi chamado de "A". Para comparação, foram coletadas duas outras marcas de carvão vegetal no mesmo supermercado. Uma de origem desconhecida, a qual, supostamente, refere-se a carvão vegetal produzido a partir de madeira nativa, denominada "B", e uma terceira marca " $C$ ", que possuía embalagem plástica de design inovador para carvão vegetal.

As caracterizações do carvão vegetal pertencente às três marcas foram realizadas no Laboratório de Química, Celulose e Energia da ESALQ/USP segundo as normas e procedimentos descritos na Tabela 1. As avaliações foram realizadas em duplicatas.

\subsection{Metodologia de desdobramento da função qualidade (QFD)}

A aplicação do QFD utilizado foi feita com base nos procedimentos descritos por Barros (2001) e Lucas Filho et al. (2010), por terem sido aplicados no setor florestal e, nessa condição, condizentes com os objetivos propostos. Nesta pesquisa, foram contempladas
Tabela 1. Fontes bibliográficas para os ensaios realizados.

Table 1. Bibliographic sources for tests conducted.

\begin{tabular}{|c|c|c|}
\hline Tipo de ensaio & Unidade & Norma/Autor \\
\hline $\begin{array}{l}\text { Determinação da } \\
\text { umidade }\end{array}$ & $\%$ & $\begin{array}{c}\text { NBR } 8112 \\
\left({ }^{*} \mathrm{ABNT}, 1986\right)\end{array}$ \\
\hline $\begin{array}{l}\text { Poder calorífico } \\
\text { superior }\end{array}$ & kcal.kg ${ }^{-1}$ & $\begin{array}{c}\text { NBR } 8633 \\
(\mathrm{ABNT}, 1984)\end{array}$ \\
\hline Densidade aparente & g. $\mathrm{cm}^{-3}$ & $\begin{array}{c}\text { NBR 11941 } \\
\text { (ABNT, 2003) }\end{array}$ \\
\hline Densidade a granel & $\mathrm{kg} \cdot \mathrm{m}^{-3}$ & $\begin{array}{c}\text { NBR } 6922 \\
(\mathrm{ABNT}, 1981)\end{array}$ \\
\hline Teor de carbono fixo & $\%$ & \multirow{3}{*}{$\begin{array}{c}\text { NBR } 8112 \\
(\mathrm{ABNT}, 1986)\end{array}$} \\
\hline $\begin{array}{l}\text { Teor de materiais } \\
\text { voláteis }\end{array}$ & $\%$ & \\
\hline Teor de cinzas & $\%$ & \\
\hline Índice de combustão & - & $\begin{array}{l}\text { Quirino \& Brito } \\
\text { (1991) }\end{array}$ \\
\hline Friabilidade & $\%$ & $\begin{array}{c}\text { NBR 7402 } \\
(\mathrm{ABNT}, 1982)\end{array}$ \\
\hline
\end{tabular}

*ABNT: Associação Brasileira de Normas Técnicas.

apenas as tabelas da qualidade exigida (descrição do produto na linguagem do consumidor) e tabela de desdobramento das características da qualidade do produto (descrições técnicas) para a construção da matriz da qualidade ou casa da qualidade, como ilustra a Figura 1.

As etapas para a aplicação do método QFD foram:

a) Aplicação do questionário para identificação das necessidades dos consumidores que utilizam o carvão vegetal para cocção;

b) Conversão das necessidades dos consumidores em qualidades exigidas;

c) Construção da tabela de desdobramento das qualidades exigidas;

d) Construção da tabela de desdobramento das características da qualidade; e

e) Construção da matriz da qualidade ou casa da qualidade.

\subsection{Análise dos dados}

Os dados levantados foram avaliados por meio da estatística descritiva, observando-se as porcentagens para os principais fatores de qualidade e da interpretação da matriz de qualidade construída. 


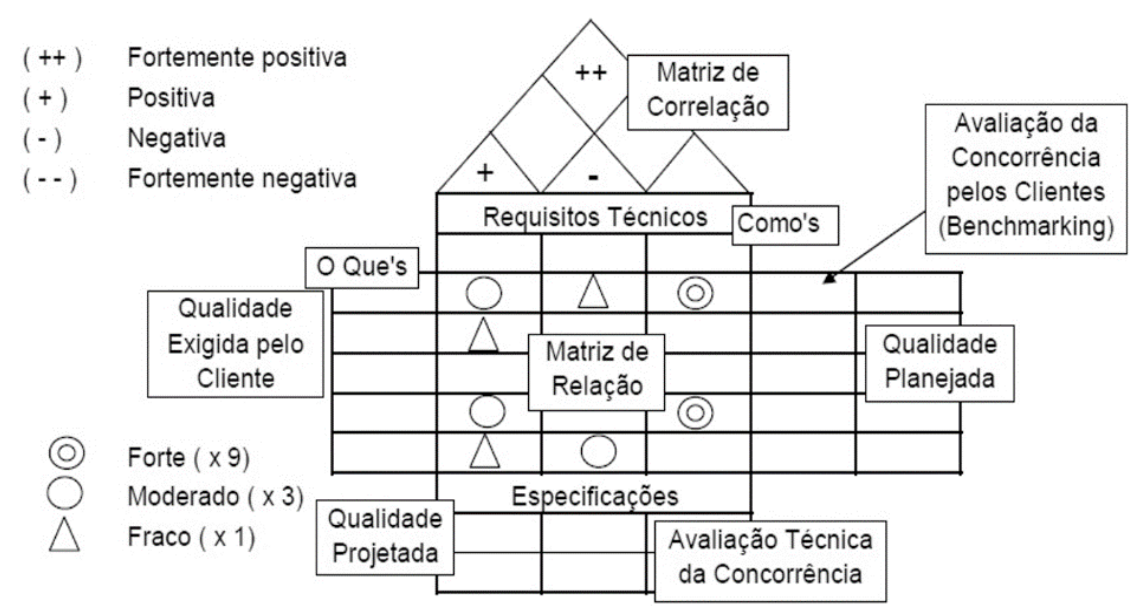

Figura 1. Casa da qualidade (Nagumo, 2005).

Figure 1. House of Quality (Nagumo, 2005).

\section{RESULTADOS E DISCUSSÃO}

A descrição do perfil dos consumidores analisados foi realizada a partir da interpretação e análise das respostas aos questionários aplicados aos consumidores de carvão vegetal. A Tabela 2 descreve o perfil dos consumidores abordados no momento da entrevista, sendo considerados os percentuais relativos ao total dos consumidores que responderam ao questionário.

Com base na Tabela 2 , nota-se que o sexo masculino representa a maioria no mercado consumidor de carvão vegetal, mas o sexo feminino também aparece em número importante, ressaltando que quase a totalidade disse fazer o próprio churrasco. Outro ponto que chama atenção é o da frequência do consumo desse insumo energético, sendo adquirido no mínimo uma vez ao mês por $90 \%$ dos entrevistados. Nota-se ainda que um elevado número de consumidores, na maioria das vezes, adquire o carvão vegetal onde adquire os demais produtos para compor a cocção de alimentos (churrasco).

\subsection{Conversão das necessidades dos consumidores em qualidades exigidas}

A Tabela 3 apresenta a conversão das principais necessidades dos consumidores em qualidades exigidas no carvão vegetal. A avaliação da qualidade pelo cliente refere-se aos aspectos característicos do insumo energético.
Tabela 2. Descrição do perfil dos consumidores entrevistados.

Table 2. Description of the profile of the consumers interviewed.

\begin{tabular}{|c|c|}
\hline $\begin{array}{c}\% \text { dos } \\
\text { entrevistados }\end{array}$ & Perfil dos consumidores \\
\hline 70 & Sexo masculino \\
\hline 55 & São casados \\
\hline 75 & Escolaridade nível médio \\
\hline 90 & $\begin{array}{c}\text { Consomem carvão vegetal pelo menos } \\
\text { uma vez ao mês }\end{array}$ \\
\hline 80 & $\begin{array}{l}\text { Mulheres que disseram fazer } \\
\text { o churrasco }\end{array}$ \\
\hline 52 & Têm entre 35 e 45 anos de idade \\
\hline 95 & $\begin{array}{l}\text { Compram o carvão onde compram os } \\
\text { demais produtos para o churrasco }\end{array}$ \\
\hline
\end{tabular}

Observa-se que as principais necessidades dos consumidores, em termos de qualidade de carvão vegetal para cocção (churrasco), foram apontadas em 11 itens e estes foram desdobrados em 17 itens secundários. Desse total, seis itens foram relativos às embalagens do carvão. Os itens "pegar fogo fácil", "formar brasas rapidamente", "ter bom rendimento", "tamanho superior a $10 \mathrm{~cm}$ ", "preço acessível" e "embalagem com alça" foram definidos pelos consumidores como muito importantes. Os itens "não apresentar umidade elevada", "ser mecanicamente resistente", "não soltar fumaça durante a cocção", "não ser pesado", "embalagem resistente à água", "embalagem com sistema de abertura" e "embalagem feita de material resistente" foram apontados como sendo de importância moderada. A 
Tabela 3. Conversão das necessidades dos consumidores em qualidades exigidas.

Table 3. Conversion of consumer needs in required qualities.

\begin{tabular}{|c|c|c|c|c|c|c|c|c|c|c|}
\hline \multirow[b]{2}{*}{$\begin{array}{l}\text { QUALIDADE } \\
\text { EXIGIDA }\end{array}$} & \multirow{2}{*}{$\begin{array}{l}\text { Grau de Importância: } \\
5 \text { - Muito Importante } \\
3 \text { - Moderado } \\
1 \text { - Indiferente }\end{array}$} & \multirow{3}{*}{ 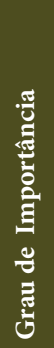 } & \multicolumn{3}{|c|}{$\begin{array}{c}\text { Avaliação } \\
\text { Competitiva } \\
\end{array}$} & \multirow[b]{3}{*}{ 章 } & \multicolumn{4}{|c|}{ Qualidade Planejada } \\
\hline & & & \multirow{2}{*}{ 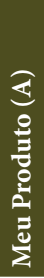 } & \multirow{2}{*}{ 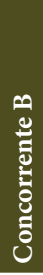 } & \multirow{2}{*}{ 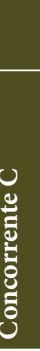 } & & \multirow{2}{*}{ 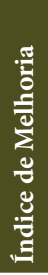 } & \multirow{2}{*}{ 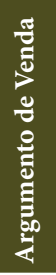 } & \multirow{2}{*}{$\begin{array}{l}\stackrel{0}{\Xi} \\
0 \\
0 \\
0 \\
0 \\
0 \\
0 \\
0\end{array}$} & \multirow{2}{*}{ 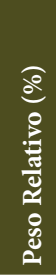 } \\
\hline Nível Primário & Nível Secundário & & & & & & & & & \\
\hline \multirow{4}{*}{ Ser fácil de acender } & Pegar fogo fácil & 5 & 5 & 3 & 5 & 5 & 1,0 & 1,5 & 7,5 & 7,1 \\
\hline & Possuir acendendor & 1 & 1 & 1 & 5 & 3 & 3,0 & 1,2 & 3,6 & 3,4 \\
\hline & Formar brasas rapidamente & 5 & 5 & 3 & 5 & 5 & 1,0 & 1,5 & 7,5 & 7,1 \\
\hline & $\begin{array}{l}\text { Não apresentar umidade } \\
\text { elevada }\end{array}$ & 3 & 5 & 1 & 3 & 5 & 1,0 & 1,2 & 3,6 & 3,4 \\
\hline Durar o bastante & Ter bom rendimento & 5 & 5 & 3 & 5 & 5 & 1,0 & 1,2 & 6 & 5,7 \\
\hline \multirow[t]{2}{*}{ Que tenha pouco pó } & $\begin{array}{l}\text { Ser mecanicamente } \\
\text { resistente }\end{array}$ & 3 & 3 & 3 & 5 & 3 & 1,0 & 1,5 & 4,5 & 4,3 \\
\hline & Pouco Friável & 1 & 5 & 3 & 5 & 5 & 1,0 & 1,2 & 1,2 & 1,1 \\
\hline Não gerar labaredas & Chamas menores que $3 \mathrm{~cm}$ & 1 & 3 & 1 & 3 & 3 & 1,0 & 1,2 & 1,2 & 1,1 \\
\hline Que não solte fumaça & $\begin{array}{l}\text { Que não solte fumaça } \\
\text { durante a cocção }\end{array}$ & 3 & 3 & 3 & 3 & 3 & 1,0 & 1,5 & 4,5 & 4,3 \\
\hline $\begin{array}{l}\text { Não tenha pedaços } \\
\text { pequenos }\end{array}$ & Tamanho superior a $10 \mathrm{~cm}$ & 5 & 5 & 1 & 3 & 5 & 1,0 & 1,5 & 7,5 & 7,1 \\
\hline Que seja barato & Preço acessível & 5 & 3 & 5 & 3 & 5 & 1,7 & 1,5 & 12,5 & 11,8 \\
\hline \multirow{3}{*}{ Ser fácil de transportar } & Embalagem com alça & 5 & 1 & 1 & 5 & 3 & 3,0 & 1,5 & 22,5 & 21,3 \\
\hline & Não seja pesado & 3 & 3 & 3 & 3 & 3 & 1,0 & 1,2 & 3,6 & 3,4 \\
\hline & $\begin{array}{l}\text { Dimensões similares a um } \\
\text { produto conhecido }\end{array}$ & 1 & 3 & 3 & 3 & 3 & 1,0 & 1,2 & 1,2 & 1,1 \\
\hline $\begin{array}{l}\text { Embalagem que proteja } \\
\text { o carvão }\end{array}$ & Resistente a água & 3 & 3 & 3 & 5 & 3 & 1,0 & 1,2 & 3,6 & 3,4 \\
\hline $\begin{array}{l}\text { Embalagem que seja fácil } \\
\text { de abrir }\end{array}$ & $\begin{array}{l}\text { Que tenha sistema de } \\
\text { abertura }\end{array}$ & 3 & 1 & 1 & 5 & 3 & 3,0 & 1,2 & 10,8 & 10,2 \\
\hline $\begin{array}{l}\text { Embalagem que não } \\
\text { rasgue fácil }\end{array}$ & $\begin{array}{l}\text { Ser feita de material } \\
\text { resistente }\end{array}$ & 3 & 3 & 3 & 5 & 3 & 1,0 & 1,5 & 4,5 & 4,3 \\
\hline
\end{tabular}

necessidade de "não gerar labaredas" assim como de "possuir acendedor" (onde este adiciona um custo relativo ao produto final) foi definida pelos consumidores como indiferentes.

Na qualidade planejada, necessidades relativas às embalagens como "possuir alça" e "ser fácil de abrir" tiveram as maiores porcentagens relativas, sendo $21,3 \%$ e $10,2 \%$, respectivamente. O preço foi outra necessidade apontada com elevada importância, com porcentagem relativa de $11,8 \%$. A Tabela 4 apresenta a matriz da casa da qualidade para os consumidores de carvão vegetal, construída com o preenchimento dos dados contidos nas tabelas de desdobramento das qualidades exigidas e tabela das características das qualidades dos produtos.
Com base na Tabela 4, é possível constatar que os itens relacionados às características da embalagem do produto como "alças" e "sistema de abertura", as quais facilitam o transporte e a abertura, respectivamente, constituíram em atributos presentes somente na marca "C", diferenciando-o dos demais produtos avaliados. Segundo Nagumo (2005), é no curso do trabalho que se definem características que busquem selecionar itens específicos de qualidade dos produtos, mantendo as características desejadas ao longo de todo o processo, o que poderia ser aplicado ao direcionamento e adequação de embalagens de carvão vegetal.

É importante salientar que no processo de produção do carvão vegetal o trabalho humano é imprescindível para atingir a qualidade. Um dos aspectos que chamam a atenção é o da capacidade do método em fazer 


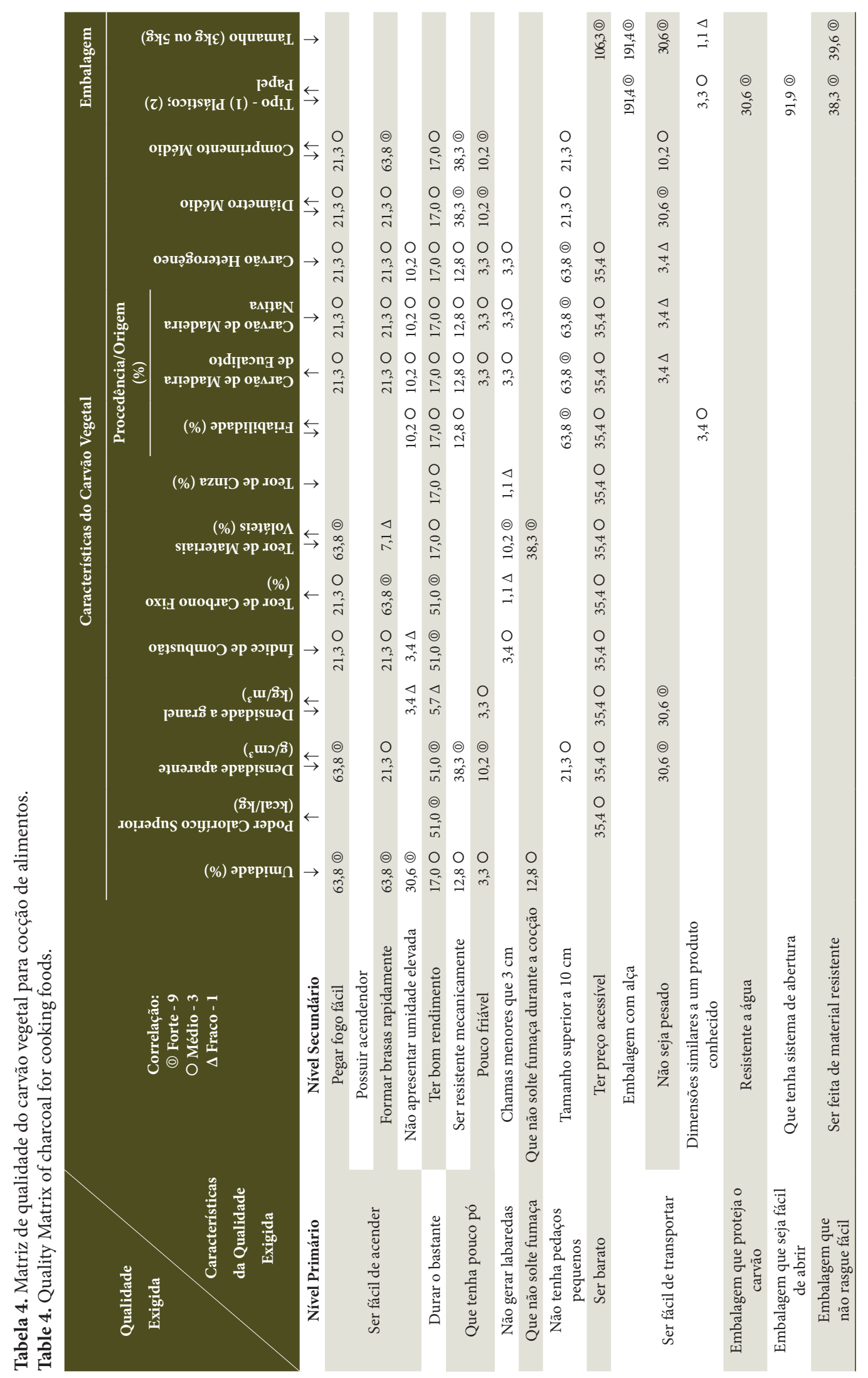




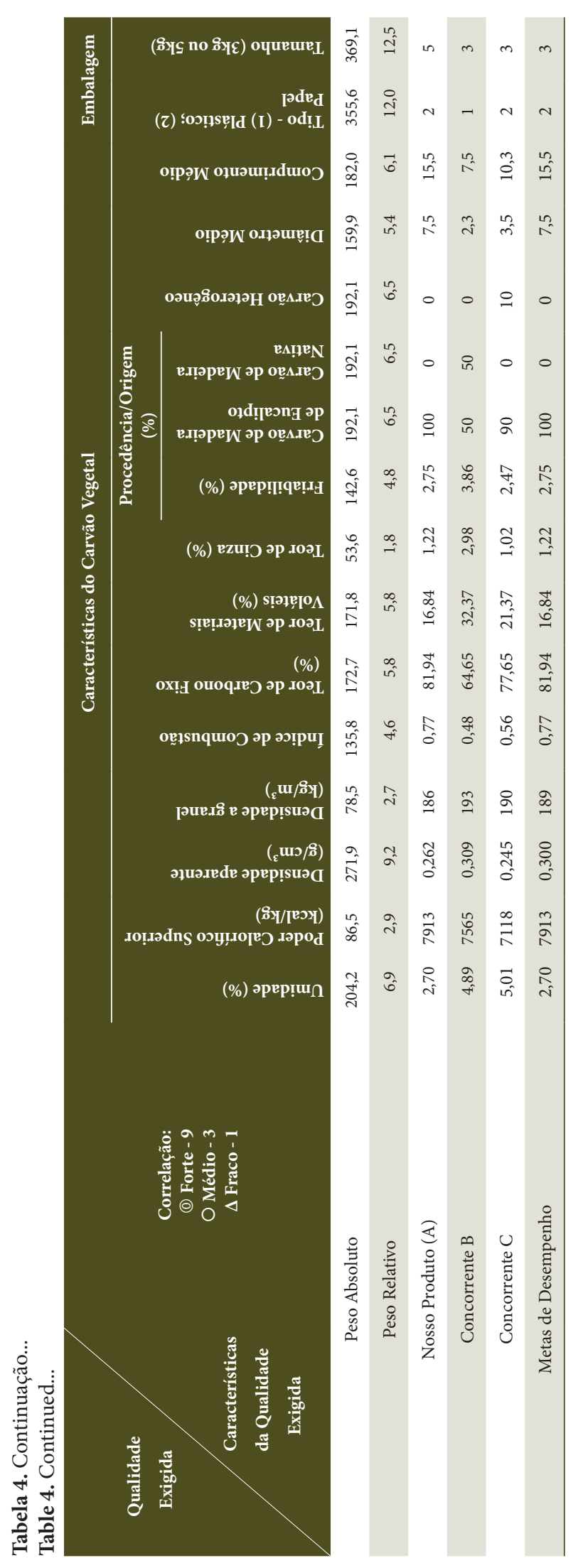




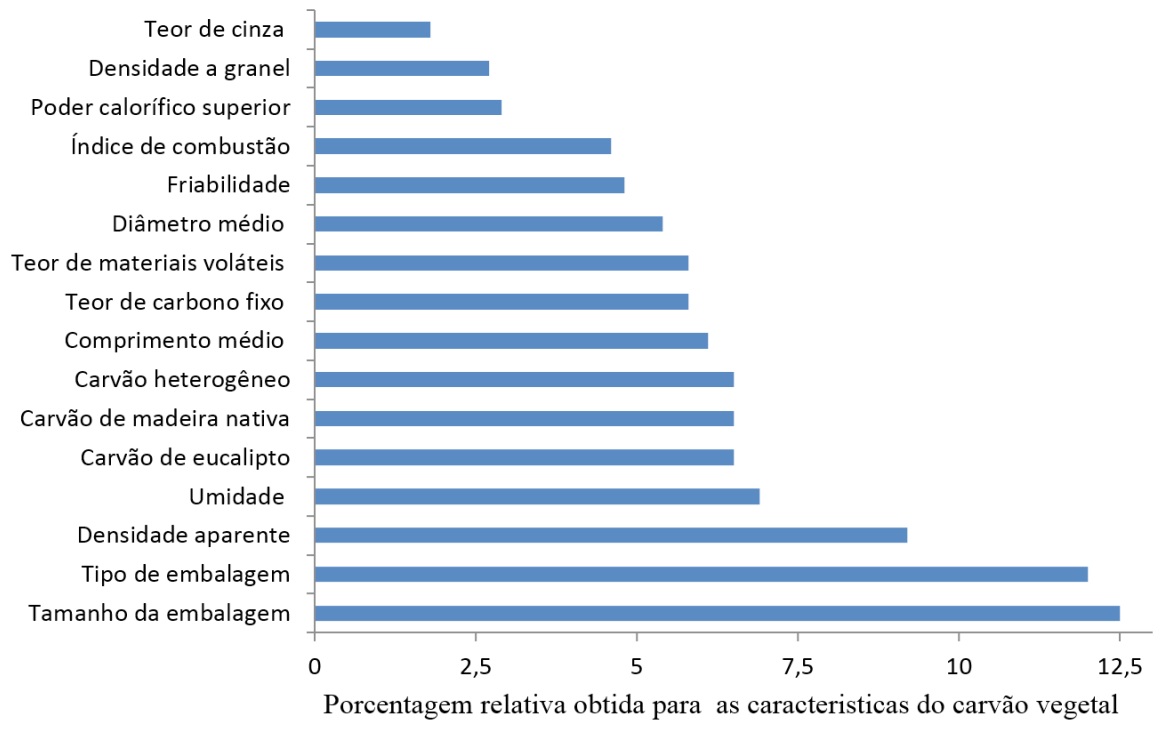

Figura 2. Porcentagens relativas das características quantitativas do carvão vegetal.

Figure 2. Relative percentages of the quantitative characteristics of charcoal.

interagir as áreas interfuncionais, pois as etapas exigem a participação de outros setores envolvidos. Este trabalho não cobriu todos os possíveis desdobramentos, sendo esperado que detalhamentos envolvendo a área gerencial da loja, bem como o processo produtivo do carvão, complementariam os procedimentos e consolidariam os resultados.

A Figura 2 apresenta a distribuição gráfica dos pesos relativos obtidos pelo desdobramento da qualidade do carvão vegetal.

As características tamanho da embalagem, tipo de embalagem e densidade aparente foram apontadas, após o desdobramento, como as mais importantes, apresentando valores de $12,5 \%, 12 \%$, e $9,2 \%$, respectivamente. A embalagem é um item importante devido a sua implicação na qualidade futura do carvão, como armazenamento, proteção contra umidade etc. Está ligada à facilidade do consumidor em transportá-la do comércio à sua residência. Quanto à densidade, sua importância já deve ser considerada desde a escolha da matéria-prima, pois reflete no carvão vegetal apresentando relação com quase todas as demais características quantificadas. Merecem atenção, principalmente, a umidade, resistência mecânica e friabilidade, pois podem se relacionar com as condições de transporte, armazenamento e rotatividade nos estabelecimentos que comercializam o produto.

\section{CONCLUSÕES}

De acordo com os resultados obtidos foi possível chegar às seguintes conclusões:

a) A metodologia QFD identificou requisitos que os clientes desejam para o carvão vegetal utilizado na cocção (churrasco).

b) A qualidade da embalagem do carvão vegetal foi uma importante característica desejada pelo consumidor.

c) Após o desdobramento, as características tamanho da embalagem, tipo de embalagem e densidade aparente tiveram os maiores pesos relativos de importância.

d) Recomenda-se uma segunda fase de estudo, avaliando o carvão vegetal produzido com base nas necessidades levantadas pelo QFD.

\section{AGRADECIMENTOS}

Ao Comércio e Indústria de Carvão São Manoel Ltda. pela disponibilização do material para o estudo, aos membros do Laboratório de Química, Celulose e Energia (LQCE/ESALQ/USP) pelo apoio e ensaios realizados e à Capes pelo fornecimento da bolsa de estudos. 


\section{STATUS DA SUBMISSÃO}

Recebido: 18 jul., 2014

Aceito: 18 dez., 2014

\section{AUTOR(ES) PARA CORRESPONDÊNCIA}

\section{Ananias Francisco Dias Júnior}

Programa de Pós-Graduação em Recursos Florestais, Escola Superior de Agricultura "Luiz de Queiroz" - ESALQ, Universidade de São Paulo - USP, Av. Pádua Dias, 11, São Dimas, CEP 13418900, Piracicaba, SP, Brasil e-mail: ananiasjr@usp.br

\section{REFERENNCIAS}

Associação Brasileira de Normas Técnicas - ABNT. NBR 6922: carvão vegetal:ensaios físicos de determinação da massa específica (densidade à granel). Rio de Janeiro; 1981.

Associação Brasileira de Normas Técnicas - ABNT. NBR 7402: carvão vegetal: determinação granulométrica. Rio de Janeiro; 1982.

Associação Brasileira de Normas Técnicas - ABNT. NBR 8633: carvão vegetal: determinação do poder calorífico. Rio de Janeiro; $1984 .$.

Associação Brasileira de Normas Técnicas - ABNT. NBR 8112: carvão vegetal: análise imediata. Rio de Janeiro; 1986.

Associação Brasileira de Normas Técnicas - ABNT. NBR 11941: madeira: determinação da densidade básica. Rio de Janeiro; 2003.

Association Française de Normalisation - AFNOR. NF EM 1860-2: appareils, combustibles solides et allume: barbecue pour la cuisson au barbecue. Saint Denis; 2005. 29 p.

Barros JWD. Planejamento da qualidade do preparo mecanizado do solo para implantação de florestas de Eucalyptus spp utilizando o método de desdobramento da função de qualidade (QFD) [dissertação]. Piracicaba: Escola Superior de Agricultura "Luiz de Queiroz", Universidade de São Paulo, 2001.

Brasil. Ministério de Minas e Energia. Balanço Energético Nacional. Brasília; 2013. [cited 2014 Jan 8]. Available from: https://ben.epe.gov.br/downloads/Relatorio_Final_ BEN_2013.pdf.
Brito JO. A escolha certa do carvão. Revista Churrasco e Churrascarias 2002; 5(24): 16.

Carnevalli JA, Miguel PC. Review, analysis and classification of the literature on QFD-Types of research, difficulties and benefits. Production Economics 2008; 114(2): 737-754. http://dx.doi.org/10.1016/j.ijpe.2008.03.006.

Cheng LC, Melo LDR Fo. QFD-Desdobramento da Função Qualidade na gestão de Desenvolvimento de Produtos. São Paulo: Blucher; 2007.

Doliveira SLD, Silva AQ. Identificação da gestão de qualidade no setor madeireiro. Revista Capital Científico 2008; 6(1): 87-106.

Lucas FC Fo, Pio NS, Ferreira DR. Método QFD como ferramenta para desenvolvimento conceitual de produtos de madeiras da Amazônia. Acta Amazonica 2010; 40(4): 675 686. http://dx.doi.org/10.1590/S0044-59672010000400006.

Milan M, Barros JWD, Gava JL. Planning soil tillage using quality function deployment. Scientia Agricola 2003; 60(2): 217-221. http://dx.doi.org/10.1590/S010390162003000200003 .

Nagumo GK. Desdobramento da função de qualidade (QFD) aplicado à produção de mudas de café (Coffea arábica L.) [dissertação]. Piracicaba: Escola Superior de Agricultura “Luiz de Queiroz", Universidade de São Paulo; 2005.

Pinto ALD, Paiva CL. Desenvolvimento de uma massa funcional pronta para tortas utilizando o método de Desdobramento da Função Qualidade (QFD). Ciência e Tecnologia de Alimentos 2010; 30(Supl 1): 36-43. http:// dx.doi.org/10.1590/S0101-20612010000500007.

Quirino WF, Brito JO. Características e índice de combustão de briquetes de carvão vegetal. Brasília: Laboratório de Produtos Florestais; 1991. p. 1-14. LPF - Série Técnica 13.

Ribeiro PG, Vale AT. Qualidade do carvão vegetal de resíduos de serraria para o uso doméstico. In: Anais da Reunião Anual da Sociedade Brasileira para o Progresso da Ciência; 2006; Florianópolis: Universidade Federal de Santa Catarina; 2006.

Rosa RA, Arantes MDC, Paes JB, Andrade SP, Moulin JC. Qualidade do carvão vegetal para uso doméstico. Journal of Biotecnology and Biodiversity 2012; 3(2): 41-48.

São Paulo. Secretaria de Agricultura e Abastecimento. Resolução no 10 SAA, de 11 de julho de 2003. Diário Oficial [do] Poder Executivo, São Paulo, SP (2003 jul.).

Warnes A. Savage barbecue: race, culture and the invention of america's first food. Geórgia: British Library; 2008. 201 p. 